\title{
Evaluation of a Distribuied Catchment Scale Water Balance Model
}

\author{
Peter A. Troch.' Marco Mancini, 2 Claldio Paniconi, ${ }^{3,4}$ and Eric F. Wood
}

\begin{abstract}
The validity of some of the simplifying assumptions in at conceptual water halance model is investigated by comparing simulation results from the conceptual model with simulation results from a three-dimensional physically based numerical model and with field observations. We examine, in particular, assumptions and simplifications related to water table dynamics. vertical soil moisture and pressure head distributions. and subsurface flow contributions to stream discharge. The conceptual model relies on a topographic index to predict saturation excess runoff and on Philip in infituation equation to predict infiltration excess runoff. The numerical model solves the three-dimensional Richards equation describing flow in variably saturated porous media. and handles seepage face boundaries, infiltration excess and saturation excess runoff production, and soil driven and atmosphere driven surface fluxes. The study catchments $(a) 7.2-\mathrm{km}^{2}$ catchment and a $0.64-\mathrm{km}^{2}$ subcatchment) are located in the North Appalachian ridge and valley region of eastern Pennsylvania. Hydrologic data collected during the MACHYDRO 90 field experiment are used to calibrate the models and to evaluate simulation results. It is found that water table dynamics as predicted by the conceptual model are close to the observations in a shallow water well and therefore, that a linear relationship between a topographic index and the local water table depth is found to be a reasonable assumption for catchment scale medeling. However, the hydraulic equilibrium assumption is not valid for the upper $100 \mathrm{~cm}$ layer of the unsaturated zone and a conceptual model that incorporates a root zone is suggested. Furthermore. theoretical subsurface flow characteristics from the conceptual model are found to be different from field observations, numerical simulation results, and theoretical baseflow recession characteristics based on Boussinesq's groundwater equation.
\end{abstract}

\section{INTRODUCTION}

Scale effects on hydrologic response have received much attention during the past decade. One of the central issues concerns the extent to which small scale details of the relevant physical processes should be represented in hydrologic models applicable over a wide range of scales. Past research efforts have resulted in the formulation of scalerelated concepts that summarize basin characteristics. Examples can be found in the works by Gupta and Waymire [1983] and Mesa and Mifflin [1986], who used the network width function to describe channel flow routing; Gupta and Waymire [1989] and Tarboton et al. [1989], who developed a stochastic theory to describe spatial variability in link heights in river networks; Beven and Kirkby [1979] and Sivapalan et al. [1987], who used the topographic index distribution of a drainage basin to model saturation excess runoff; and Wood et al. [1988] and Wood et al. [1990], who introduced the concept of the representative elementary area (REA) as the scale at which continuum assumptions concerning small scale heterogeneity hold.

Based on these ideas, conceptual models have been developed to describe and explain hydrologic response at the basin scale. What these models have in common is their

\footnotetext{
'Laboratory of Hydrology and Water Management, Ghent University, Gent, Belgium.

2 Dipartimento di Ingegneria Idraulica, Ambientale e del Rilevamento. Politecnico di Milano, Milan, Italy.

3 Dipartimento di Metodi e Modelli Matematici, Universita di Padova. Padua. Italy.

${ }^{4}$ Now at CRS4. Cagliari, Italy.

Water Resources Program. Department of Civil Engineering and Operations Research. Princeton Lniversity, Princeton. New Jersey.

Copyright 1993 by the American Geophysical Union.

Paper number $936 \mathrm{~W} 00398$

(0)43-139793/93WR-00398\$05.00
}

representation of physical process dynamics using analytically tractable solutions to governing equations. To obtain such closed form solutions, it is in general necessary to consider simplifications in the mathematical formulation of the processes, such as linearizing the governing equations or assuming a restricted set of initial and boundary conditions. Moreover, different and often contrasting analytical solutions are used to represent the various hydrologic processes of interest. It is then hoped that the hydrologic model will be capable of simulating some average response of the basin. In this spirit, calibration and validation of conceptual models is often based on lumped hydrologic fluxes such as total discharge at the catchment outlet. However, current usage of conceptual models is not restricted to prediction of average hydrologic behavior. In environmental studies, for instance, accurate prediction of the temporal and spatial structure of each component of the hydrologic cycle has become increasingly important.

It is the purpose of this paper to evaluate some of the simplifying assumptions in a distributed basin scale water balance model. The conceptual model under study is described in detail by Famiglietti et al. [1992]. The model relies on a topography-soil index to predict saturation excess runoff [Beven and Kirkby. 1979; Sivapalan et al., 1987] and on Philip's equation [Brutsciert. 1976; Philip, 1957a, b] to predict infiltration excess runoff. In this paper, we examine conceptualizations concerning the spatial distribution and temporal evolution of the water table depth. the distribution of soil moisture and pressure head in the unsaturated zone. and the characteristics of base flow recession. The topography-soil index, an index of hydrologic similarity / Wood et al. 1990], is used to compute the local depth to the water table. In the model this water table depth will determine the storage capacity and hydraulic properties in the unsaturated zone, and it therefore plays a central role in the generation of surface runoft. The local storage deficit is calculated based 
on a hydraulic equilibrium assumption for pressure head. from which the vertical distribution of soil moisture is obtained. This hydraulic equilibrium assumption also yields the surface soil moisture value which in turn is used to calculate the parameters in Philip's infiltration equation. It is further assumed that during a rainfall event the average water table depth remains constant. Immediately after cessation of rainfall the change in groundwater storage is proportional to the infiltrated and drained volume, and this information is used to update the water table depth. During an interstorm period the water table depth is a function of evaporation and subsurface flow, and is updated at every time step. In the model subsurface contributions to total streamflow depend on an exponential relationship between base flow and groundwater storage.

To investigate the assumptions described above we compare simulation output from different components of the conceptual model with results obtained from a threedimensional numerical model and with field observations. The numerical model used in this study is described by Paniconi and Wood [1993] and is based on the threedimensional transient Richards equation. This model handles evaporation and precipitation inputs at the catchment surface and predicts saturation excess and infiltration excess runoff generation. The evaluation of the conceptual model is carried out at two basin scales: for a $7.2-\mathrm{km}^{2}$ catchment and for a $0.64-\mathrm{km}^{2}$ subcatchment. These study catchments (WE-38 and WD-38 Mahantango Creek) are located in the North Appalachian ridge and valley region of eastern Pennsylvania. Detailed hydrologic information for both catchments was collected during the 12-day Multisensor Airborne Campaign 1990 (MACHYDRO 90). One of the objectives of this campaign is to apply the multisensor data in detailed water balance studies of the regulating effect of soil moisture on hydrologic processes.

Numerical models based on the Richards equation have been used in the past to simulate hillslope and catchment scale hydrologic processes [e.g., Freeze, 1971; Smith and Hebbert, 1983; Binley et al., 1989]. These physically based models have proved useful in evaluating the underlying assumptions in conceptual models. Examples can be found in the works by Gan and Burges [1990a, b] (rainfall-runoff models on small hypothetical catchments), Sloan and Moore [1984] (one- and two-dimensional subsurface storm flow models), and Ibrahim and Brutsaert [1968] and Reeves and Miller [1975] (one-dimensional infiltration models to test the time compression approximation). The numerical model used in this study is based on the following assumptions and limitations: flow is laminar and isothermal, inertial forces and chemical gradients are neglected, and the air phase is continuous and at atmospheric pressure. In addition, the model does not account for hysteresis and it is assumed that the porous medium is isotropic. Finally, we consider only flow within the soil matrix, neglecting flow through macropores.

In the following section we present the main features of the conceptual model and the numerical model. Both models can handle spatially and temporally variable inputs and are designed to take advantage of digital elevation data bases and of information extracted from these data bases by topographic analysis. Mechanisms of streamflow generation are discussed. Geophysical characteristics of the sludy catchments are given in section 3.1. The Mahantango Creck watershed is characterized by long even-crested ridges. which alternate with broad, rolling valleys. The catchment experiences a humid climate with approximately $1000 \mathrm{~mm}$ of annual precipitation, distributed uniformly throughout the year. The data and parameters used in the two models are described in sections 3.2 and 3.3 , with additional discussion in section 3.4 of initial conditions and the estimation of an effective depth to the water table. The calibration of both models is discussed in section 3.5 and is based on a comparison between observed and simulated runoff volume.

In the conceptual model the local water table depth is assumed to be a linear function of the topography-soil index. This hypothesis is tested in section 4.1 by comparing the distribution of the topography-soil index with the distributions of the water table depth generated by the numerical model for subcatchment WD-38 at the end of a 12-day simulation period. To minimize the effect of initial conditions, longer test runs with the numerical model are also performed. In section 4.2 assumptions in the conceptual model about the temporal evolution of the local and average water table depth are studied. Piezometric observations from a shallow and a deep well are compared with simulation results from both the conceptual and numerical models. In the following section the hydraulic equilibrium assumption for the vertical distribution of soil moisture is tested by generating moisture profiles at fixed points along a hillslope situated in subcatchment WD-38 using the numerical model. In section 4.4 the characteristics of base flow recession for the conceptual and numerical models are compared with observations and with analytical solutions to Boussinesq's hydraulic groundwater equation.

\section{DESCRIPTION OF THE MODELS}

\subsection{Conceptual Water Balance Model}

The conceptual water balance model used in this study is developed by Sivapalan et al. [1987] and Famiglietti et al. [1992]. We present here a brief description of the basic equations of the model. The water balance for a catchment with drainage area $A$ is given by

$$
A e=A p-Q-\frac{d S_{u}}{d t}-\frac{d S_{g}}{d t}
$$

where $t$ is time, $e$ is the catchment average evaporation rate, $p$ is the lumped rainfall intensity, $Q$ is the streamflow at the basin outlet, $S_{u}$ is the volume of water stored in the unsaturated zone, and $S_{g}$ is the groundwater storage. Other contributions to the water balance. such as deep percolation and the storage in surface water bodies, are assumed to be of minor importance and are neglected.

2.1.1. Sireamflow generation. The conceptual model predicts soil saturation and its relationship to both saturation excess and infiltration excess surface runoff generation using spatially variable soil and topographic data. The initial storage capacity in the unsaturated zone is a function of the depth to the water table. The local depth to the water table $z_{i}$ can be computed as [Sivapalan 't al., 1987]

$$
z_{1}=z-\frac{1}{f}\left\{\ln \left(\frac{a T_{e}}{T_{1} \tan \beta}\right)-\lambda\right\}
$$


$\Sigma$ areal average of $z_{i}$;

$T_{i}$ local value of the transmissivity coefficient $T=$ $\kappa_{s_{1}} f$ :

$K_{3}$ saturated hydraulic conductivity at the surface:

$f$ describes the exponential decay of hydraulic conductivity with depth:

$\ln \left(T_{p}\right)$ expected value of $\ln \left(T_{i}\right)$;

$\lambda$ expected value of the topographic index $\ln (a /$ tan $\beta)$ :

a local draining area per unil contour length:

$\beta$ land surface slope angle.

The derivation of (2) is based on the assumption that the water table is nearly parallel to the soil surface and that the saturated hydraulic conductivity $K_{s}$ declines exponentially with depth $z_{d}$ according to

$$
K_{s}(z)=K_{s_{0}} \exp \left(-f z_{d}\right)
$$

Assuming hydraulic equilibrium for the vertical pressure distribution, the local storage capacity $S_{i}$ can be expressed in terms of $z_{i}$ and given soil parameters as

$$
S_{i}=\left(\theta_{s}-\theta_{r}\right)\left\{z_{i}-\psi_{c}-\frac{1}{1-B}\left[\left(\frac{\psi_{c}}{z_{i}}\right)^{B} z_{i}-\psi_{c}\right]\right\}
$$

where $\theta_{s}$ is the saturation moisture content and $\theta_{r}$ is the residual moisture content. The air entry pressure head value $\psi_{c}$ and the pore size distribution index $B$ are the parameters in the soil moisture characteristic relationship formulated by Brooks and Corey [1964]:

$$
\begin{array}{lr}
\theta(\psi)=\theta_{r}+\left(\theta_{s}-\theta_{r}\right)\left(\frac{\psi_{c}}{\psi}\right)^{B} & \psi \leq \psi_{c} \\
\theta(\psi)=\theta_{s} & \psi \geq \psi_{c} \\
K(\psi)=K_{s}\left(\frac{\psi_{c}}{\psi}\right)^{2+3 B} & \psi \leq \psi_{c} \\
K(\psi)=K_{s} & \psi \geq \psi_{c}
\end{array}
$$

where $\theta$ is volumetric moisture content, $\psi$ is pressure head, and $K$ is hydraulic conductivity. Whenever the cumulative infiltration volume exceeds the local soil moisture storage capacity, saturation excess runoff is generated.

The infiltration excess component of the model applies the time compression approximation to Philip's equation to compute the local infiltration rate $g_{i}$ under local erratic rainfall $p_{\text {; }}$ [Famiglietti et al., 1992]:

$$
g_{i}=\min \left[g_{i}^{*}(G), p_{i}\right]
$$

in which $G$ is cumulative infiltration and the local infiltration capacity $g *$ is calculated as

$$
g_{i}^{*}(G)=c K_{S_{11}}\left\{1+\left[\left(1+\frac{4 c K_{S_{11}} G}{S_{r}^{2}}\right)^{1 / 2}-1\right]^{-1}\right\}
$$

where $S_{r}$ is sorptivity and $c K$, accounts for the effect of gravity on the infiltration rate. The parameter $c$ ranges from 0.5 to 1.0 and depends on the saturation of the soil profile. Analytical expressions for $c$ and $S$, are given in the work by Sivapalan and Wood [1986]. Infiltration excess runoff is generated on those parts of the catchment where $p_{i}>g_{i}^{*}$.
The model assumes an exponemial relitionship between base flow and groundwater storatge such that the bate flow contribution $Q_{b}$, to totil streamflow is given by

$$
Q_{1}=Q_{0} \sin (-f)
$$

where $Q_{0}$ represents suburfice flow when $z=0$. During a rainstorm the average depth to the water table is kept fixed and redistribution of soil moisture is neglected. After esssittion of rainfall a new value for $\bar{F}$ is calculated taking into account the total amount of uater infiltrated and draned.

The total streamflow for the catchment is obtained by summing the contributions to surface runoff from saturation excess, infiltration excess, and subsurface flow. In this version of the model overland flow and channel flow routing are not considered.

2.1.2. Evaporation. Saturated areas are allowed to evaporate at the potential rate $c_{n}$ (atmosphere controlled stage). As the soil near the surface dries out the moisture delivery rate is limited by the properties of the soil profile (soil controlled stage). The model uses an analytical solution to the one-dimensional desorption problem and again applies the time compression approximation which results in the following expression:

$$
e_{a}=\min \left[e_{a}^{*}\left(E_{a}\right), e_{p}\right]
$$

in which $e_{a}$ is the actual evaporation rate and $e^{*}$ represents the evaporation capacity as a function of cumulative evaporation $E_{a}$ :

$$
e_{a}^{*}\left(E_{a}\right)=S_{a}^{2 / 2} E_{a}
$$

where $S_{e}$ is the desorptivity, which varies with soil moisture content. Transpiration is not considered in this version of the model.

During interstorm periods the water table is updated at each time step, taking into account evaporative and drainage losses.

\subsection{Numerical Model}

The numerical catchment simulation model is presented in the works by Paniconi [1992] and Paniconi and Wood [1993]. We will highlight the main features of the model. The three-dimensional Richards equation with pressure head $\psi$ as the dependent variable can be written as

$$
S(\psi) \frac{\partial \psi}{\partial t}=\Gamma \cdot\left(K_{s} K_{r}(\psi) \nabla(\psi+z)\right)
$$

where $z$ is the vertical coordinate, positive upward, and the hydraulic conductivity $K$ is expressed as a product of the conductivity at saturation and the relative conductivity $K$, An extension of the van Genuchten characteristic equations [van Genuchten and Nielsen. 1985] is used to describe the nonlinear dependencies of $H, K_{r}$, and specific moisture capacity $S$ on the pressure head [Paniconi. 1992]:

$\theta(\psi)=\theta_{r}+\left(\theta_{s}-\theta_{r}\right)[1+\beta]^{-m} \quad \psi \leq \psi_{0}$

$\theta(\psi)=\theta_{r}+\left(\theta_{s}-\theta_{r}\right)\left[1+\beta_{0}\right]^{-m}+S_{s}\left(\psi-\psi_{0}\right) \quad \psi \geq \psi_{0}$ 
TABLE I. Soil Parameters for W' -38 Mahantango Creek

\begin{tabular}{|c|c|c|c|c|c|c|c|c|c|}
\hline \multirow{3}{*}{$\begin{array}{c}\text { Soil } \\
\text { Number }\end{array}$} & \multirow[b]{3}{*}{ Soil Name } & \multirow{3}{*}{$\begin{array}{c}\text { Soil } \\
\text { Texture }\end{array}$} & \multirow{3}{*}{$\begin{array}{c}K_{\text {no }} \\
\text { mhour }\end{array}$} & \multirow[b]{3}{*}{$\theta$} & \multirow[b]{3}{*}{$\theta_{+}$} & \multicolumn{4}{|c|}{ Water Retention Parameters } \\
\hline & & & & & & \multicolumn{2}{|c|}{ Brooks-Corey } & \multicolumn{2}{|c|}{$\begin{array}{c}\text { van } \\
\text { Genuchien }\end{array}$} \\
\hline & & & & & & $u_{c}, \mathrm{~m}$ & $B$ & $\psi_{1}, \mathrm{~m}$ & $n$ \\
\hline 71 & Albrights & sill loam & 0.036 & 0.501 & 0.015 & 0.21 & 0.211 & 0.43 & 1.29 \\
\hline 57 & Alvira & silt loam & 0.036 & 0.501 & 0.015 & 0.21 & 0.211 & 0.43 & 1.29 \\
\hline 8 & Basher & silt loam & 0.036 & 0.501 & 0.015 & 0.21 & 0.211 & 0.43 & 1.29 \\
\hline 145 & Berks & silt loam & 0.073 & 0.501 & 0.015 & 0.21 & 0.211 & 0.43 & 1.29 \\
\hline 45 & Calvin & silt loam & 0.057 & 0.501 & 0.015 & 0.21 & 0.211 & 0.43 & 1.29 \\
\hline 73 & Conyngham & silt loam & 0.036 & 0.501 & 0.015 & 0.21 & 0.211 & 0.43 & 1.29 \\
\hline 32 & Dekalb & sandy loam & 0.090 & 0.450 & 0.041 & 0.15 & 0.322 & 0.24 & 1.38 \\
\hline 54 & Hartleton & silt loam & 0.057 & 0.501 & 0.015 & 0.21 & 0.211 & 0.43 & 1.29 \\
\hline 149 & Klinesvil & silt loam & 0.090 & 0.501 & 0.015 & 0.21 & 0.211 & 0.43 & 1.29 \\
\hline 75 & Laidig & gravel loam & 0.090 & 0.460 & 0.027 & 0.11 & 0.220 & 0.17 & 1.25 \\
\hline 66 & Leck Kill & silt loam & 0.057 & 0.501 & 0.015 & 0.21 & 0.211 & 0.43 & 1.29 \\
\hline 69 & Meckesville & loam & 0.036 & 0.501 & 0.015 & 0.21 & 0.211 & 0.43 & 1.29 \\
\hline 70 & Meckesville & stony loam & 0.090 & 0.501 & 0.015 & 0.21 & 0.211 & 0.43 & 1.29 \\
\hline 38 & Shelmadine & silt loam & 0.036 & 0.501 & 0.015 & 0.21 & 0.211 & 0.43 & 1.29 \\
\hline 47 & Weickert & silt loam & 0.073 & 0.501 & 0.015 & 0.21 & 0.211 & 0.43 & 1.29 \\
\hline
\end{tabular}

$$
\begin{aligned}
& S(\psi)=\frac{d \theta}{d \psi}=\frac{(n-1)\left(\theta_{s}-\theta_{r}\right) \mid \psi^{n-1}}{\left|\psi_{s}\right|^{n}(1+\beta)^{m+1}} \quad \psi \leq \psi_{0} \\
& S(\psi)=\frac{d \theta}{d \psi}=S_{s} \quad \psi \geq \psi_{0} \\
& K_{r}(\psi)=(1+\beta)^{-5 m / 2}\left[(1+\beta)^{m}-\beta^{m}\right]^{2} \quad \psi \leq 0 \\
& K_{r}(\psi)=1 \quad \psi \geq 0
\end{aligned}
$$

where $S_{s}$ is the specific storage, $m=1-1 / n, \beta=\left(\psi / \psi_{s}\right)^{n}$, $\beta_{0} \equiv \beta\left(\psi_{0}\right), \psi_{s}$ is a fitting parameter, and $n$ can be interpreted as a pore size distribution index; $\psi_{0}$ is a continuity parameter which is calculated from (14) given $S_{s}$. The exponential relationship (3) is used to model vertical heterogeneity of saturated hydraulic conductivity. Hysteresis effects on moisture redistribution in the soil profile are not taken into account. We remark here that different soil moisture characteristic relationships are used in the conceptual model (equations (5) and (6)) and the numerical model (equations (13) and (15)). Any discrepancy this may cause is minimized by fitting both sets of equations to the same field observations (see Table 1). Since the soils in Mahantango Creek show a wide pore size distribution. the van Genuchten water retention equation fitted the observed data better than the Brooks-Corey equation. Troch et al. [1993] and P. A. Troch et al. (Hydrologic controls of large floods in a small basin: North Appalachian case study. submitted to the Journal of Hydrology, 1993) have developed a more general formulation of the conceptual model based on the van Genuchten characteristic equations. The effect of the use of different soil characteristic curves in catchment modeling is under investigation.

A finite element Galerkin discretization in space and a finite difference discretization of the time derivative term is used to solve (12) numerically. The resulting system of nonlinear equations is linearized using either Picard or Newton iteration [Paniconi et al., 1991].

The catchment simulation model comprises two programs: a grid generator which constructs the finite element mesh and initializes various parameters, and the actual simulation program which numerically solves the three-dimensional Richards equation over a specified time period for a given set of boundary and initial conditions.

2.2.1. Streamflow generation. The potential inflows to the model consist of precipitation (positive) and evaporation (negative) flux inputs at the catchment surface. The actual (simulated) inflows are determined according to the type of boundary condition imposed, and during a simulation the model automatically adjusts this boundary condition according to changes in pressure head and flux values at the surface. When the potential flux is positive, the difference between potential and actual soil inflow is the total runoff. Surface runoff is produced when the surface becomes saturated, either due to a rising water table (saturation excess mechanism) or to the infiltration capacity of the soil falling below the rainfall rate (infiltration excess mechanism). In both cases the boundary condition at the point on the surface where saturation occurs switches from a Neumann type (atmosphere controlled infow) to a Dirichlet type (soil controlled inflow). Subsurface runoff in the model is produced at seepage faces or when subsurface water exits the soil matrix from a saturated region on the surface (return flow). Overland flow (surface runoff and return flow) generated at a point on the catchment is routed to the stream using a time delay determined from the overland flow velocity (assumed constant for the catchment) and the shortest distance from the point to the stream. In this version of the model channel flow is not considered.

2.2.2. Evaporation. When evaporation is atmosphere controlled and the pressure head at a point on the surface becomes smaller than the "air dry" pressure head value $\psi_{\min }$ [Hillel, 1980, p. 121], the boundary condition at that point is switched from specified flux (Neumann) to constant head (Dirichlet) and thus the evaporation process becomes soil controlled. The boundary condition switches back to a Neumann type when the magnitude of the computed flux across the soil surface exceeds the magnitude of the potential evaporation rate, or when a rainfall event hegins. R, not 
extraction is not included in the numerical model and therefore the model cannot simulate evaporation from vegetated surfaces when the actual rate falls below the potential rate.

\section{DEscription OF THE CATChMENTS} AND MODEL INPLTS

\subsection{Mahantango Creek Experimental Catchment}

The Mahantango Creek watershed (approximately $\mathbf{4 2 0}$ $\mathrm{km}^{2}$ ) is characterized by long. even-crested ridges $300-400$ $m$ in elevation, which alternate with broad, rolling valleys, $150-300 \mathrm{~m}$ in elevation. The mountain ridges run in the NE-SW direction. The ridges are underlain by erosionresistant sandstones, orthoquartzite, and conglomerate. The valleys are underlain by less erosion-resistant shales, siltstones, and sandstones [Urban, 1977]. The catchments used in this study are part of the Mahantango Creek watershed. WE-38 Mahantango Creek is one of the experimental catchments of the Agricultural Research Service (ARS) of the U.S. Department of Agriculture (USDA). The total drainage area is $7.2 \mathrm{~km}^{2}$ and it includes a $0.64-\mathrm{km}^{2}$ subcatchment, WD-38, which has been the subject of intensive hydrologic research [e.g., Engman, 1974; Engman and Rogow'ski, 1974].

The catchments experience a humid climate, typical for the northeastern United States, with approximately $1000 \mathrm{~mm}$ of annual precipitation, distributed uniformly throughout the year. The average rainfall during the month of July (the month of the MACHYDRO 90 experiment) is $104 \mathrm{~mm}$ [Gburek, 1977]. The frequent rains keep the soils at or near field capacity, except near the surface. Even the fragipan soils near the stream, which have only limited moisture holding capacity and root penetration as a result of the confining layer, remain relatively moist because of this frequent rainfall and their proximity to the high water table. Soil moisture is generally variable only to about the $100 \mathrm{~cm}$ depth [Gburek, 1977]. Below this depth soil moisture content remains nearly constant at near field capacity throughout the year. Based on measurements from more than 30 groundwater wells, Urban [1977] constructed a water table map for WE-38. The groundwater profile is highly correlated with topography. Because of the relatively high moisture content of the soils the actual evapotranspiration (ET) is at or near its potential rate much of the time. There are short periods, however, during which soil moisture deficit limits evapotranspiration. Gburek [1977] estimated that baseflow at WE-38 is about $70 \%$ of yearly streamflow.

\subsection{Hydrologic Data}

The hydrologic data used in this study were gathered during the 12-day Multisensor Airborne Campaign 1990 (MACHYDRO 90). The objective of this campaign is to study the role of soil moisture and its regulating effect on hydrologic processes. The experiment was held from July 9 to July 20,1990 . During this period the spatial and temporal distribution of precipitation was measured by 14 rain gages with $0.2 \mathrm{~mm}$ accuracy at a sampling interval of $15 \mathrm{~min}$. Figure 1 shows the catchment average rainfall recorded during the 12-day period. The observed accumulated rainfall is $66 \mathrm{~mm}$. This rainfall fell during the first half of the experiment. The maximum observed rainfall intensity is about $20 \mathrm{~mm} /$ hour, a value lower than the minimum saturated hydraulic conduc-
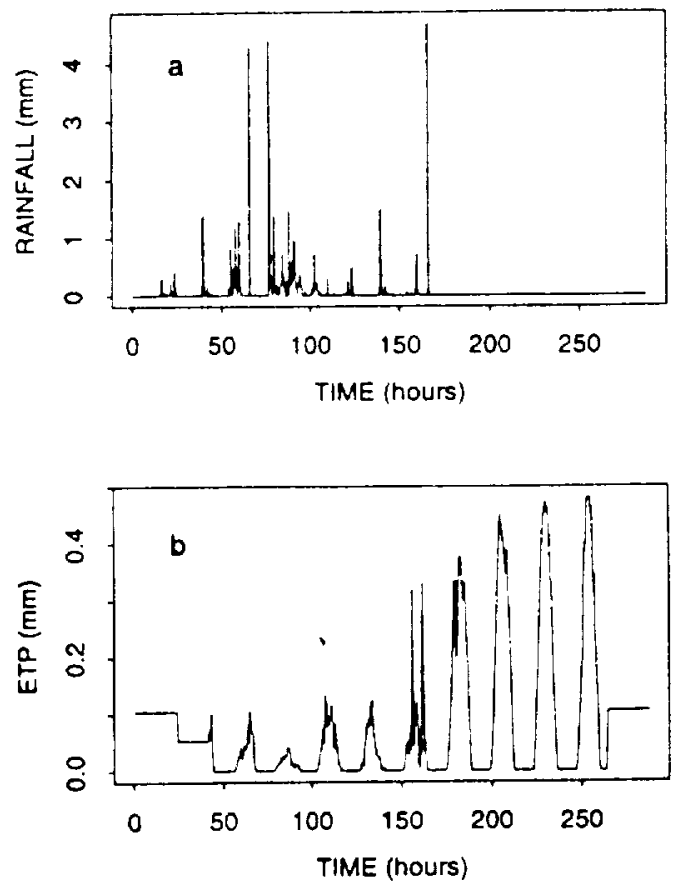

Fig. 1. (a) Areal average precipitation data for the 12-day period July 9-20, 1990 calculated from 15 -min observations at 14 rain gages. (b) Estimated potential evaporation based on 30-min measured net radiation and estimates based on weather reports (flat lines at the beginning and end of the graph).

tivity reported for the soils in Mahantango Creek. Infiltration excess runoff is thus impossible during this period.

Potential evaporation from July 11 to July 19 is calculated based on the Priestley-Taylor method using measured net radiation from a micrometeorological station. Radiation was measured at a sampling interval of $30 \mathrm{~min}$. For July 9, 10, and 20 , when the meteorological station was not operating, daily potential evaporation values of $5,2.5$, and $5 \mathrm{~mm}$, respectively, are estimated based on weather reports. The total potential evaporation for the 12-day period is $45 \mathrm{~mm}$. The temporal evolution of potential evaporation is shown in Figure 1. Based on these meteorological observations a strong drydown can be expected during the second half of the experiment.

The temporal evolution of the phreatic surface was observed at four piezometers. The measured depth to the water table ranged from 1 to $4 \mathrm{~m}$. Soil samples were taken along fixed transects, from which the gravimetric and volumetric moisture content in the top soil layer could be estimated. These data are nct used in this study but will be analyzed and compared with the models' output in future studies. Streamflow is observed at the outlet of catchment WE-38 and subcatchment WD-38 (Figure 2). The level response at 180 hours in catchment WE-38 is an artifact. No attempts were made to correct for this anomalous observation since no detailed information about the data collection was available to the authors. During the 12-day experiment, it is estimated that only 1 or $2 \%$ of the total rainfall became direct runofi. Base flow tends to be low during summer months. During the experiment the volume of base flow was about equal to the direct runoff volume. The remaining rainfall observed during the experiment is either stored in the unsaturated and groundwater zones or is evaporated into the atmosphere. 

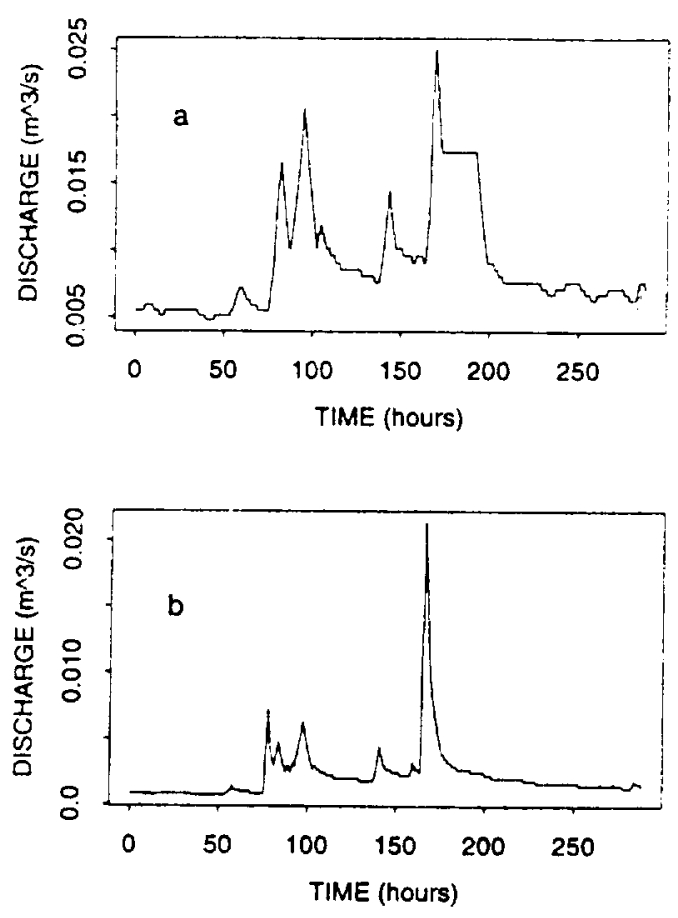

Fig. 2. Observed streamflow data for the 12-day period July $9-20$, 1990 for $(a)$ catchment WE-38 and (b) catchment WD-38.

Figure 2 demonstrates the nonlinear response to rainfall of the two basins during the experiment. The initial storm response is almost negligible. The runoff production of the two basins during the last rainfall event is more pronounced and is dominated by the saturation excess mechanism.

\subsection{Model Parameters}

3.3.1. Soils. In WE-38 Mahantango Creek, 15 different soil types can be identified (Table 1). From Table 1 it can be seen that the spatial distribution of $\theta_{s}, \theta_{r}, \psi_{c}\left(\psi_{s}\right)$, and $B(n)$ can be neglected for catchment WE-38, and therefore for subcatchment WD-38 as well. The following parameter values are used to characterize the soil water retention properties in WE-38 and WD-38: $\theta_{s}=0.501, \theta_{r}=0.015$, $\psi_{c}=0.21 \mathrm{~m}, \psi_{s}=0.43 \mathrm{~m}, B=0.211$, and $n=1.29$. The areal average value of saturated hydraulic conductivity at the surface $\bar{K}_{s_{0}}$ is $0.062 \mathrm{~m} /$ hour. However, this parameter varies considerably from 0.036 to $0.090 \mathrm{~m} /$ hour and therefore is explicitly taken into account in both models. We refer to Rogowski et al. [1974] and Loague and Freeze [1985] for a detailed soil map of both WE-38 and WD-38. The value of specific storage $S_{s}$ used in (13) and (14) is $0.005 / \mathrm{m}$. For the numerical model the parameter $\psi_{\min }$, which controls the switching of evaporation boundary conditions, was set at a value low enough to ensure that actual evaporation remained
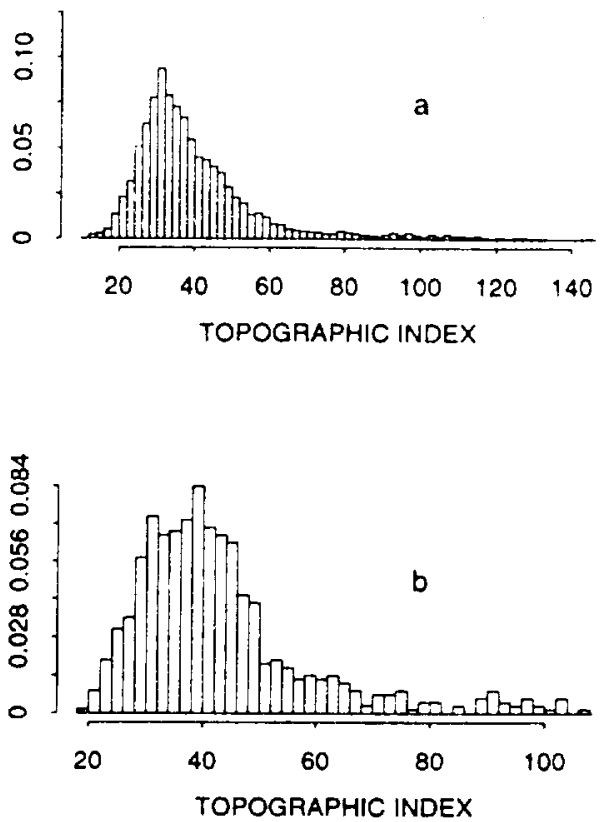

Fig. 3. Distribution of the local topographic index $10 \ln (a / \tan \beta)$ for $(a)$ catchment WE-38 and $(b)$ catchment WD-38.

at its potential rate throughout the simulation, in accordance with field observations.

3.3.2. Topography. Catchment topography is represented by a $30 \times 30 \mathrm{~m}$ U.S. Geological Survey digital elevation model (DEM). From this DEM the topographic index $\ln (a / \tan \beta)$ can be determined for each grid square. Figure 3 shows the distribution of the topographic index in the two catchments. Sivapalan et al. [1987] used a threeparameter gamma distribution to model the topographic index:

$$
f_{T}(x)=\frac{1}{\chi \Gamma(\phi)}\left(\frac{x-\mu}{\chi}\right)^{\phi-1} \exp \left\{-\frac{x-\mu}{\chi}\right\}
$$

where $x=\ln (a / \tan \beta), \phi$ is a shape parameter, $\chi$ is a scale parameter, $\mu$ is a shift parameter, and $\Gamma$ () represents the gamma function. The parameter values for (16) applied to the two catchments were estimated by the method of moments and are given in Table 2 .

3.3.3. Numerical parameters. In the numerical model the vertical soil profile is discretized into six layers of thickness $5,5,12.5,75,127.5$, and $275 \mathrm{~cm}$, with the thinnest layers closest to the surface. This results in an impervious layer (the base of the catchment) at a depth of $5 \mathrm{~m}$, running parallel to the land surface. The horizontal discretization is taken equal to the grid size in the digital elevation modei, that is $30 \mathrm{~m}$ by $30 \mathrm{~m}$. The spatial discretization of subcatchment WD-38 yields 3804 elements and 4935 nodes. The

TABLE 2. Topographic Characteristics for Catchments WE-38 and WD-38

\begin{tabular}{|c|c|c|c|c|c|c|}
\hline \multirow[b]{3}{*}{ Catchment } & \multicolumn{3}{|c|}{ Topographic Index, In $(a / \tan \beta)$} & \multirow{2}{*}{\multicolumn{3}{|c|}{ Gamma Distribution Parameters }} \\
\hline & & & Coefficient of & & & \\
\hline & Mean & Variance & Variation & $\phi$ & $x$ & $\mu$ \\
\hline WE-38 & 4.03 & 2.88 & 0.42 & 5.651 & 0.714 & 0.0 \\
\hline WD-38 & 4.37 & 2.48 & 0.36 & $7.7(00)$ & 0.567 & 0.0 \\
\hline
\end{tabular}


sensitivity of the simulated results to the grid resolution is an important issue, especially for areas in the catchnent with large vertical pressure variations. Such areas would be near the streams and other runoff producing areas. Panicomi and Wood [1993] investigate the accuracy of the model to grid resolution and show that for grid sizes like those used in this study, good model simulations will be obtained. An adaptive time stepping algorithm is used in the numerical model. with a minimum time step size of 5 min and a maximum of 15 min (equal to the sampling interval of the rainfall data). During each time step the numerical solution is assumed to converge when the maximum change in nodal pressure head between nonlinear iterations is less than $6 \mathrm{~cm}$. An average of four nonlinear iterations per time step is required for the simulations.

\subsection{Initial Conditions}

In the conceptual model the average depth to the water table $\bar{z}$ determines the initial catchment wetness conditions. For short-term simulations the output of the conceptual model is highly sensitive to this parameter, and it should therefore be carefully determined. Recently, Troch et al. [1993] developed a physically meaningful technique to estimate the effective depth to the water table, as a measure of the initial storage capacity of a basin. The analysis is based on Boussinesq's hydraulic groundwater equation and uses streamflow measurements at the outlet of the basin. Boussinesq's equation describes the water table height $h(x, t)$ in the case of outflow into a stream channel from an idealized unconfined aquifer with width $L$ placed on a horizontal impermeable layer:

$$
\frac{\partial h}{\partial t}=\frac{k}{n_{e}} \frac{\partial}{\partial x}\left(h \frac{\partial h}{\partial x}\right)
$$

where $t$ represents the time since the start of the recession, $x$ is horizontal distance, $h(x, t)$ is the transient free groundwater surface profile, $k$ is the hydraulic conductivity of the aquifer, and $n_{e}$ is the drainable or effective porosity (sometimes referred to as specific yieid). For small $t$, as the outflow rate $q$ at $x=0$ starts, the effect of the impermeable wall at $x=L$ (representing the divide) is negligible and the solution to (17) can be taken to be the same as if $L=\infty$. Polubarinova-Kochina [1962] has presented an exact solution for this case. The response of the aquifer water table to sudden drainage at $t=0$ is not unlike a propagating wave. As soon as the wave reaches the end of the aquifer, at $x=$ $L$, the small $t$ solution is no longer valid. At this point, Boussinesq's solution can be used. Boussinesq [1904] obtained an exact solution to the nonlinear differential equation by assuming that the initial water table has the form of an inverse incomplete beta function [see also PolubarinovaKochina, 1962, pp. 515-517]. This solution is not valid for small $t$, when the aquifer is close to being fully saturated. Based on this large time solution, Troch et al. [1993] derived the following expression for the effective water table height:

$$
\bar{h}=0.773 D\left[1+1.115\left(\frac{k D}{n_{e} L^{2}}\right) t\right]^{-1}
$$

where $D$ represents depth to the bedrock. The catchment base flow $Q_{b}$ can now be expressed as [Troch et al. . 1993a]

$$
Q_{h}=5.772 k(D-z)^{2} D_{d} L_{t}
$$

where $k$ and $D$ can be considered as catchment scale effective values of hydraulic conductivity and depth to the bedrock, respectively, $D$, represents drainage density, and $L$, is the lotal length of the perennial channels. One can determine $D$, once $k$ is known, by defining a critical value of the base flow $Q$.. corresponding to a situation where it is assumed that the aquifers start to behave in accordance with Boussinesq's solution:

$$
Q_{1}=3.450 \mathrm{k} \mathrm{D}^{ } \mathrm{D}_{d} L_{\mathrm{r}}
$$

Equation (19) can then be used to estimate $z$ from observed base flow at the start of the simulation period.

To estimate the parameters in (19) and (20), a method for base flow analysis based on the following relationship is adopted:

$$
d Q d t=\Phi(Q)
$$

Brutsaert and Nieber [1977] have shown that, for several solutions based on the Dupuit-Boussinesq hydraulic theory, $\Phi($ ) can be written in the form of a power function:

$$
d Q / d t=-a_{1} Q^{b_{1}}
$$

where $a_{1}$ and $b_{1}$ can be related to hydraulic and geomorphologic characteristics of the basin. Using Boussinesq's solution it follows immediately that [Brutsaert and Nieber, 1977]

$$
a_{1}=\frac{4.804 k^{1 / 2} L_{t}}{n_{e^{A^{3}}}^{3 / 2}} \quad b_{1}=3 / 2
$$

For the small time solution it can be shown that

$$
a_{1}=\frac{1.133}{k n_{e} D^{3} L_{t}^{2}} \quad b_{1}=3
$$

In Figure 4 we have plotted historical observed daily recession flow data for WE-38 and WD-38 versus its time derivative. Only uninterrupted recession flow data starting the second day after the cessation of rainfall are considered. For WE-38 (Figure $4 a$ ) the data are fitted by a regression line (not shown on the figure) with slope 1.498 and a correlation coefficient of 0.88 ; the regression for WD-38 (Figure $4 b$ ) has a slope of 1.35 and a correlation coefficient of 0.89 . This suggests that the Dupuit-Boussinesq hydraulic theory holds: the observed slope is close to the theoretical slope of 1.5 . Figure 4 shows a lower envelope with slope 1.5 that excludes about $5 \%$ of the data points. A lower envelope is chosen to eliminate other outflow components such as overland flow, interflow, channel drainage, and evaporation losses. However, the exact position of this lower envelope is uncertain. Troch et al. [1993] suggest the use of a 5 or $10 \%$ lower envelope. In this study a lower envelope excluding $5 \%$ of the data points is adopted. The corresponding intercept values $a_{1}$ are $1.7861 \times 10^{-6}\left(\mathrm{~m}^{3} / \mathrm{s}\right)^{-1 / 2}$ for WE-38 and $8.6792 \times$ $10^{-6}\left(\mathrm{~m}^{3} / \mathrm{s}\right)^{-12}$ for WD-38.

The critical base flow value $Q$, represents an upper limit for the applicability of the large time solution. Troch $\mathrm{ct} \mathrm{al}$. [1993] therefore suggest that this parameter should be estimated by the abscissa value of the intersection of the lower envelope curves with slopes 1.5 and 3 on a log-log diagram. They observed that, for a river basin in Belgium, the value of $Q$, is rather insensitive to the actual position of these lines 

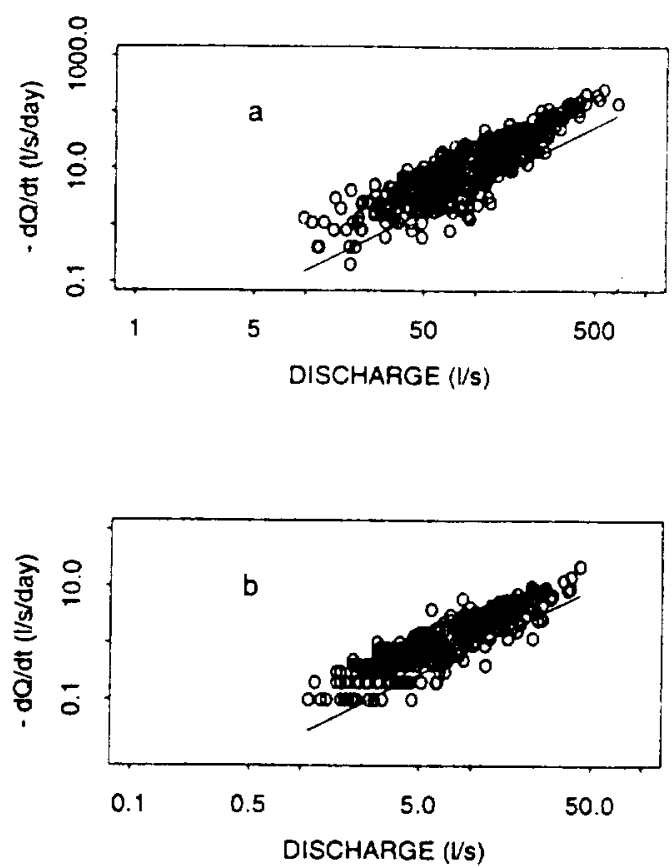

Fig. 4. Log-log plot of $-d Q / d t$ versus observed discharge $Q$ for (a) catchment WE-38 and (b) catchment WD-38; also shown are the lower envelopes (solid lines) which exclude $5 \%$ of the data points.

However, for the catchments under study, the slope of 3 is not apparent in the data. Therefore the critical value is estimated to be equal to the maximal observed base flow value in Figure $4\left(0.500 \mathrm{~m}^{3} / \mathrm{s}\right.$ and $0.050 \mathrm{~m}^{3} / \mathrm{s}$, respectively).

Table 3 summarizes the results of applying (23) and (20). Results are given for a range of $n_{e}$ values, namely, from 0.02 to 0.07 . These are reasonable values for the catchments under study [Freeze and Cherry, 1979, p. 61]. The geomorphologic parameters $D_{d}$ and $L_{t}$ are estimated from the DEM data by means of an automated extraction algorithm [Band, 1986]. This algorithm produces a mapping of stream channels, ridges, and drainage basins. The total length of perennial channels, as defined by the blue lines on the topographic maps for WE-38 is about $12 \mathrm{~km}$. which results in a drainage density of $1.6 \times 10^{-3} \mathrm{~m}^{-1}$; corresponding values for WD-38 are $0.9 \mathrm{~km}$ and $1.5 \times 10^{-3} \mathrm{~m}^{-1}$.

The observed base flow at the beginning of the experiment is $0.006 \mathrm{~m}^{3} / \mathrm{s}$ for WE-38 and $0.001 \mathrm{~m}^{3} / \mathrm{s}$ for WD-38. By means of (17) and using an average value of drainable porosity of 0.04 , the effective depth to the water table $z$ is of the order of $3.3 \mathrm{~m}$ for WE-38 and $2.3 \mathrm{~m}$ for WD-38. These

TABLE 3. Estimated Aquifer Parameters for Catchments WE-38 and WD-38

\begin{tabular}{lccccc}
\hline & \multicolumn{2}{c}{ WE-38 } & \multicolumn{2}{c}{ WD-38 } \\
Drainable & \multicolumn{2}{c}{$\left(Q_{c}=0.500 \mathrm{~m}^{3} / \mathrm{s}\right)$} & & \multicolumn{2}{c}{$\left(Q_{c}=0.050 \mathrm{~m}^{3} / \mathrm{s}\right)$} \\
\cline { 2 - 3 } \cline { 5 - 6 } & $k, \mathrm{~cm} / \mathrm{h}$ & $D . \mathrm{m}$ & & $k, c \mathrm{~m} / \mathrm{h}$ & $D . \mathrm{m}$ \\
\hline 0.02 & 53 & 7.16 & 134 & 5.19 \\
0.03 & 120 & 4.78 & 301 & 3.46 \\
0.04 & 213 & 3.58 & 536 & 2.60 \\
0.05 & 333 & 2.87 & 837 & 2.08 \\
0.06 & 480 & 2.39 & 1205 & 1.73 \\
0.07 & 653 & 2.05 & 1641 & 1.49 \\
\hline
\end{tabular}
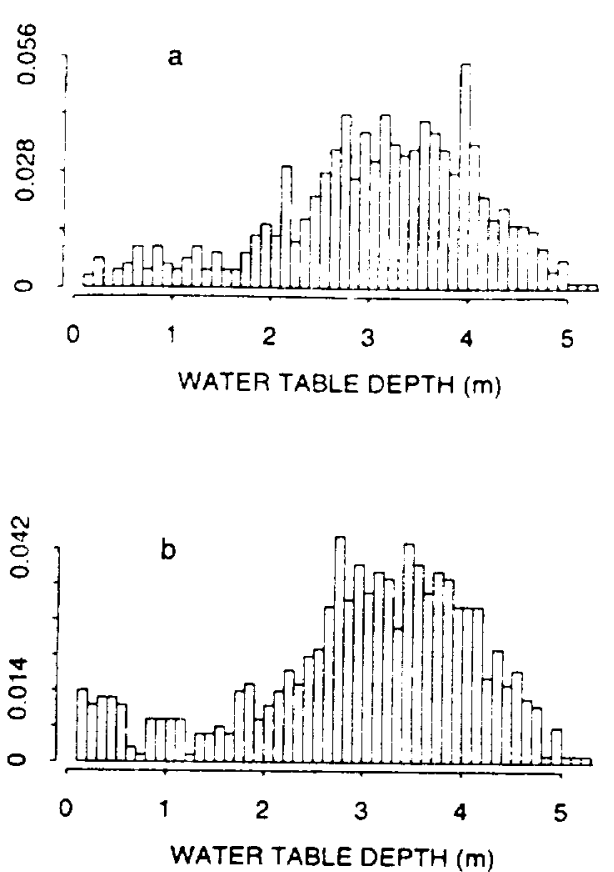

Fig. 5. (a) Distribution of the local water table depth at the start of the numerical simulation as calculated from (2). (b) Distribution of the local water table depth at the end of the numerical simulations for the 12-day period of the MACHYDRO 90 experiment.

values are used as initial conditions in the conceptual water balance model.

The initial conditions required for a transient simulation with the numerical model are nodal pressure head values. The initial heads are generated based on knowledge of the initial water table distribution given by (2) (see Figure $5 a$ ). The local water table depth is converted into a vertical pressure head distribution using the hydrostatic assumption. This means that if at a given location the depth to the water table is $3 \mathrm{~m}$, the pressure head at the surface node is $-3 \mathrm{~m}$.

\subsection{Model Calibration}

Both the conceptual and the numerical model were calibrated in order to preserve total runoff volume. During the simulation period the dominating runoff production mechanism is saturation excess. This is not surprising considering the rainfall characteristics during MACHYDRO 90 and the soil characteristics of the basin. The parameter $f$ was used in both models as a fitting parameter. For different soil types and land use. Beven [1982] reports fitted values for the parameter $f$ to observed soil hydraulic characteristics. The values range from $1.0 \mathrm{~m}^{-1}$ to about $10.0 \mathrm{~m}^{-1}$. For sandy loam to silt loam soils a typical value of $2.5 \mathrm{~m}^{-1}$ is suggested. For one of the soil types in the catchment (Albrights: see Table 1). Rogowsti et al. [1974] estimated this parameter to be of order $1.2 \mathrm{~m}^{-1}$. In this study a catchment-wide effective value of $f=2.5 \mathrm{~m}^{-1}$ was found for the conceptual nodel, and a value of $1.05 \mathrm{~m}^{-1}$ was used for the numericil model. It is noted that the optimized values of $f$ correspond to observed values reported in the literature.

The model parameters that were estimated or inferred from data outside the 12 day simulation period are as follows: soil parameters described in section 3.3. I lestimated 
from detailed soil survey datal. topographic parameters described in section 3.3.2 (from LSGS DEM data) and initial water table depths described in section 3.4 (inferred from historical streamflow recession data). This leaves only $f$ which was estimated during model calibration, as described above.

\section{Evaluation of thF Conchptua. Wathr Balancf MODEi}

\subsection{Spatial Distribution of Local Water Table Depth}

In the conceptual model the difference between the local water table depth and its areal average is a linear function of the combined topography-soil index $\ln \left(a T_{c} / T_{i} \tan \beta\right)$, as expressed by (2). Based on ficld evidence, Wood et al. [1990] concluded that the deviation of the topographic variable from its expected value $\lambda$ is far greater than the standard deviation of the local values of the transmissivity coefficient. Therefore variability in the transmissivity coefficient will have a relatively small effect on the predicted patterns of water table depths in the conceptual model compared to the effect of topographic variability. The observations of Urban [1977] support this result for Mahantango Creek. Figure $5 a$ shows the initial distribution of local water table depth for the WD-38 catchment calculated based on (2). This distribution is used in the initial conditions for both the conceptual and the numerical model. During simulations with the numerical model the water table profile, as a function of space ( $x$ and $y$ coordinates) and time, is calculated based on the three-dimensional equations governing flow in porous media. At the end of the 12-day simulation period which involved hydrologic fluxes of significant magnitude $(66 \mathrm{~mm}$ of rainfall and $45 \mathrm{~mm}$ of potential evaporation), the numerical model preserves, to a certain extent, the initial distribution of the water table depth. This suggests that the estimate of the initial conditions based on (2) is consistent with groundwater hydraulics and that the use of (2) in a basin scale water balance model is reasonable.

To test the effect of initial conditions, longer numerical simulations for the WD-38 catchment were performed. During the first 100 days of a 400-day simulation, we apply zero-flux boundary conditions at the surface (no precipitation and no evaporation), in order to allow redistribution within the saturated zone. For the next 150 days a constant rainfall rate of $0.1 \mathrm{~mm} /$ hour is applied as the surface boundary condition. This is followed by a second zero-flux boundary condition period of 150 days. The distribution of the water table depth at the end of the first 100 days is shown in Figure $6 a$, while the distribution at the end of the simulation period for the same catchment is given in Figure $6 b$. After the first 100-day period the distribution of the local water table depth closely resembles the initial distribution. This means that, even after a longer simulation period, the model shows no tendency to drift away from the initial conditions set by (2). At the end of the 400-day simulation, however, the distribution tends to become more uniform. We also observe a shift in the areal average water table depth due to the large atmount of rainfall $(360 \mathrm{~mm}$ ) during this period. We conclude from these tests that the linear relationship between water table depth and topographic index given by (2) appears to be a reasonable assumption except when the catchment is highly stressed or far removed from its steady or equilibrium state as mav occur during prolonged periods of rainfall.
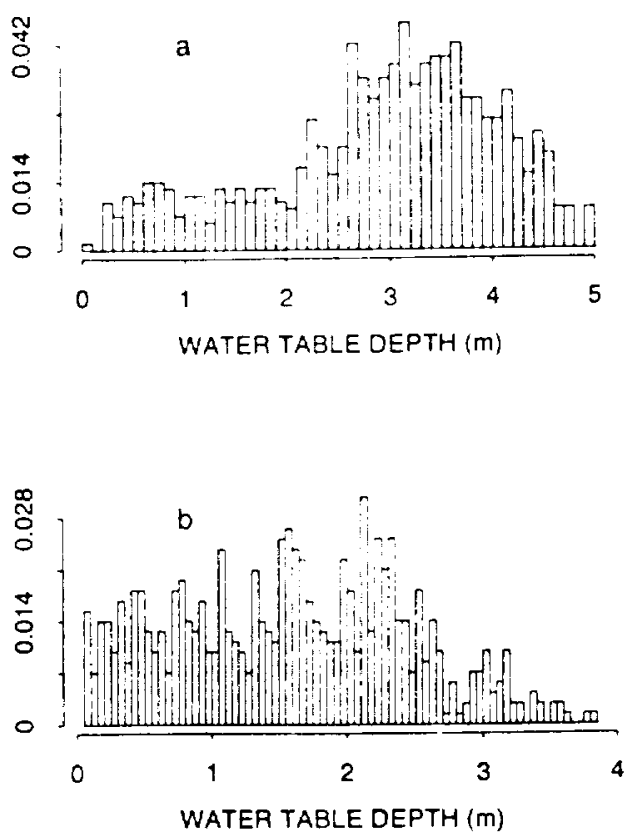

Fig. 6. (a) Distribution of the local water table depth after 100 days of a 400 -day numerical simulation, with zero-flux boundary conditions at the surface for the first 100 days. (b) Distribution of the local water table depth at the end of the 400-day numerical simulation, with total rainfall of $360 \mathrm{~mm}$.

\subsection{Temporal Evolution of Water Table Depth}

During a rainstorm the conceptual model does not update the depth to the water table. Immediately after cessation of rainfall a new value of mean water table depth is calculated taking into account the infiltrated and drained volume from the previous storm. This aspect of the model is apparent in Figure $7 a$. Line 1 in Figure $7 a$ shows the variation of areal average water table depth about its mean value, calculated with the conceptual model for WD-38. The mean water table depth during the simulation is $2.13 \mathrm{~m}$. During the dry down at the end of the experiment the evolution of mean water table depth is controlled by evaporative and drainage losses. Line 2 in Figure $7 a$ shows the variation of areal average water table depth about its mean value, as computed with the numerical model for WD-38. The calculated mean value is $2.85 \mathrm{~m}$. The updating of the water table is now controlled by the percolation and a much smoother curve is obtained.

The variation of local water table depth with respect to its local mean as computed by the conceptual model is similar to line 1 in Figure $7 a$. This is due to the fact that the soil characteristics which are controlling the updating of the water table are assumed to be spatially invariant and that runoff production is dominated by the saturation excess mechanism. Therefore we can compare the areal average simulation results for the conceptual model to observed variations in water table for the catchment. Line 3 in Figure $7 b$ shows the simulated variation in water table depth by means of the numerical model for a site along the transect shown in Figure 8 . The mean water table depth for this site during the experiment is $1.43 \mathrm{~m}$. Comparing line 3 in Figure $7 b$ with line 2 in Figure $7 a$ we can see that the variation of areal average water table depth calculated with the numerical model reflects the variation for sites in the eatchment exhibiting deeper water table depths. Therefore it is inter- 

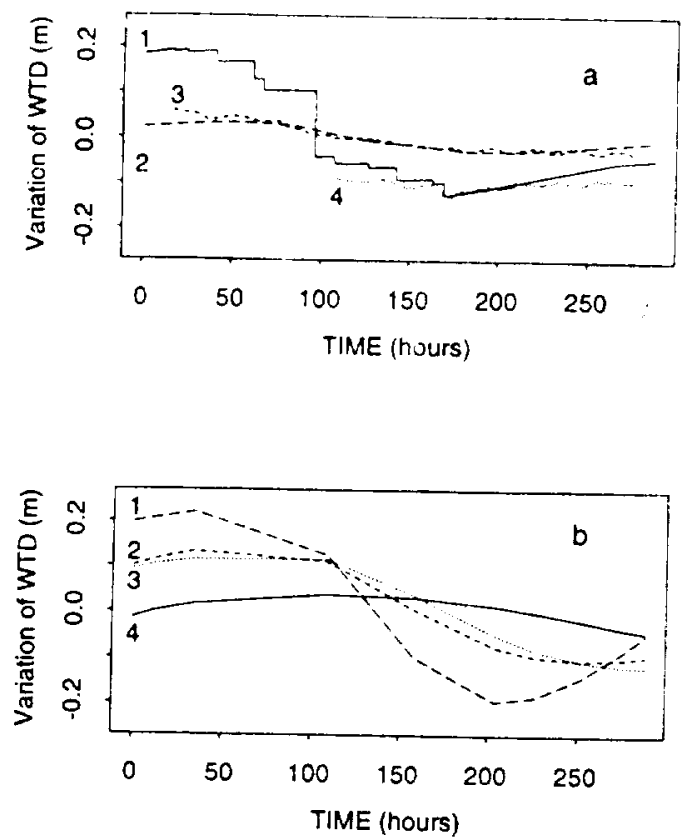

Fig. 7. (a) Line 1: variation about the mean value $(2.13 \mathrm{~m})$ of the areal average water table depth (WTD) calculated with the conceptual model for the 12-day period; line 2: variation about the mean value $(2.85 \mathrm{~m})$ of the areal average WTD calculated with the numerical model for the 12-day period; line 3: observed variation of WTD in a deep well (mean value $3.63 \mathrm{~m}$ ); and line 4 : observed variation of WTD in a shallow well (mean value $0.91 \mathrm{~m}$ ). This line is shifted from the zero mean to overlap with line 1 . (b) Numerically simulated evolution of local water table depth at four locations along a transect; line 1: mean WTD value $0.32 \mathrm{~m}$ (node closest to the channel); line 2: mean WTD value $1.13 \mathrm{~m}$; line 3 : mean WTD value $1.43 \mathrm{~m}$; and line 4 : mean WTD value $1.92 \mathrm{~m}$ (node farthest from the channel).

esting to compare the areal average simulation results for the numerical model to observed variations in deeper piezometers. Line 4 in Figure $7 a$ shows the observed variation in depth to water table for a shallow piezometer (mean value during the experiment: $0.91 \mathrm{~m}$ ) and line 3 shows the observed variation for a deeper well (mean value: $3.63 \mathrm{~m}$ ). The irregular fluctuation of the shailow well observations is

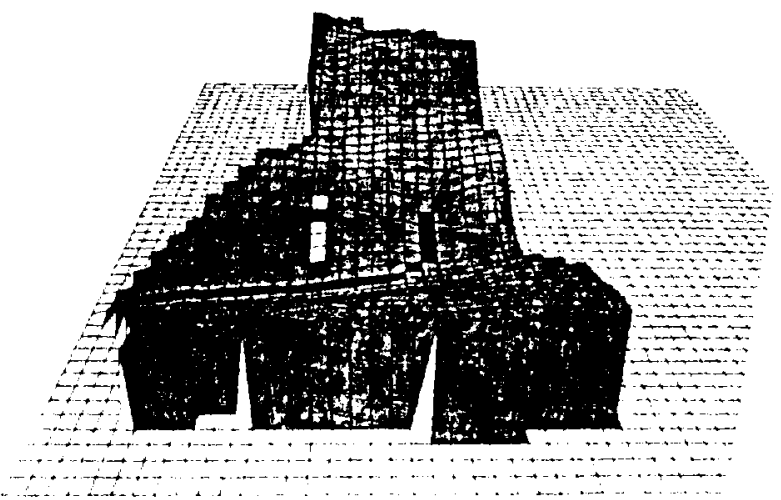

Fig. 8. Elevation image of subcatchment WD-38 $1.30 \times 30 \mathrm{~m}$ grid resolution) showing stream (heavily shaded pixelal and location of the transect of four surface nodes selected for vertical profile output (unshaded pixels). prohably due to evapotranspitation louses. The grounduater ydrograph, as observed by the shallow piezomeler, shows more or less the same temporal evolution as simulated hy the concentual model. During the last ratinfall period the water balance model predicts a rise in water table of ahout $2-3 \mathrm{~cm}$ and the observations show a comparable evolution. After the rainfall the simulated drop in water table is in good agreement with the response in the shallow well. After a few days, however, the conceptual model overestimates the rate of decline of the water table. The evolution of mean water table depth as calculated by the numerical model and the obser. vation for the same period in the deeper well are in remarkably good agreement. The absolute mean values are different $(2.85$ and $3.63 \mathrm{~m}$, respectively) but the general trend in lines 2 and 3 is very close. The diurnal variation in the observation in the deep well during the last days of the experiment (which is also exhibited by other piezometers, not shown in Figure 7) is explained by diurnal variations in atmospheric pressure. Similar results were obtained using data observed in the other piezometers.

These results seem to indicate that the simplifying assumption in the conceptual model concerning the temporal evolution of the water table holds for those parts of the catchment with a shallow water table. This could be explained by the fact that the time delay between infiltration and percolation to the water table is small for these sites. To further test this hypothesis we computed, from the numerical simulation of WD-38. the temporal evolution of the water table for different locations along a hillslope transect. The four unshaded pixels in Figure 8 show the location of the surface nodes selected for detailed vertical profile output. The results for the 12-day simulation period are given in Figure $7 b$. It is clear from this graph that infiltration and percolation effects are more damper' uphill (line 4), where the water table is deeper. The range of variation of depth to the water table close to the channel (line 1) compares reasonably well to the one predicted by the conceptual model. It has a mean value of $0.30 \mathrm{~m}$.

It is interesting to refer to earlier research concerning groundwater level fluctuations performed in the same basin. Urban [1977] reports groundwater recharge events for three wells in September 1973. For the shallow well (water table at about $1 \mathrm{~m}$ below the land surface) a similar response to rainfall, as observed in the shallow well during MACHYDRO 90 , is reported. For a comparable rainfall event the variation is a few centimeters. However, the response measured in the deep well (water level at about $18 \mathrm{~m}$ below the land surface) is much more pronounced than that observed during MACHYDRO 90 , with a variation of the order of $1 \mathrm{~m}$. The measured water table in this well is in the outcrop of a sandstone. The sandstone is covered with coarse gravelly colluvial soils. These geologic conditions are not represented in the numerical simulations reported here.

\subsection{Soil Moisture Profile's}

The conceptual model calculates unsaturated zone storage capacity based on the hydraulic equilibrium assumption. This assumption also affects the local infiltration parameters needed in Philip's equation. Figure 9 shows simulated pressure head profiles produced by the numerical model for catchment WD-38. The locations of these vertical profiles in the catchment are those shown in Figure 8 . We can see that 

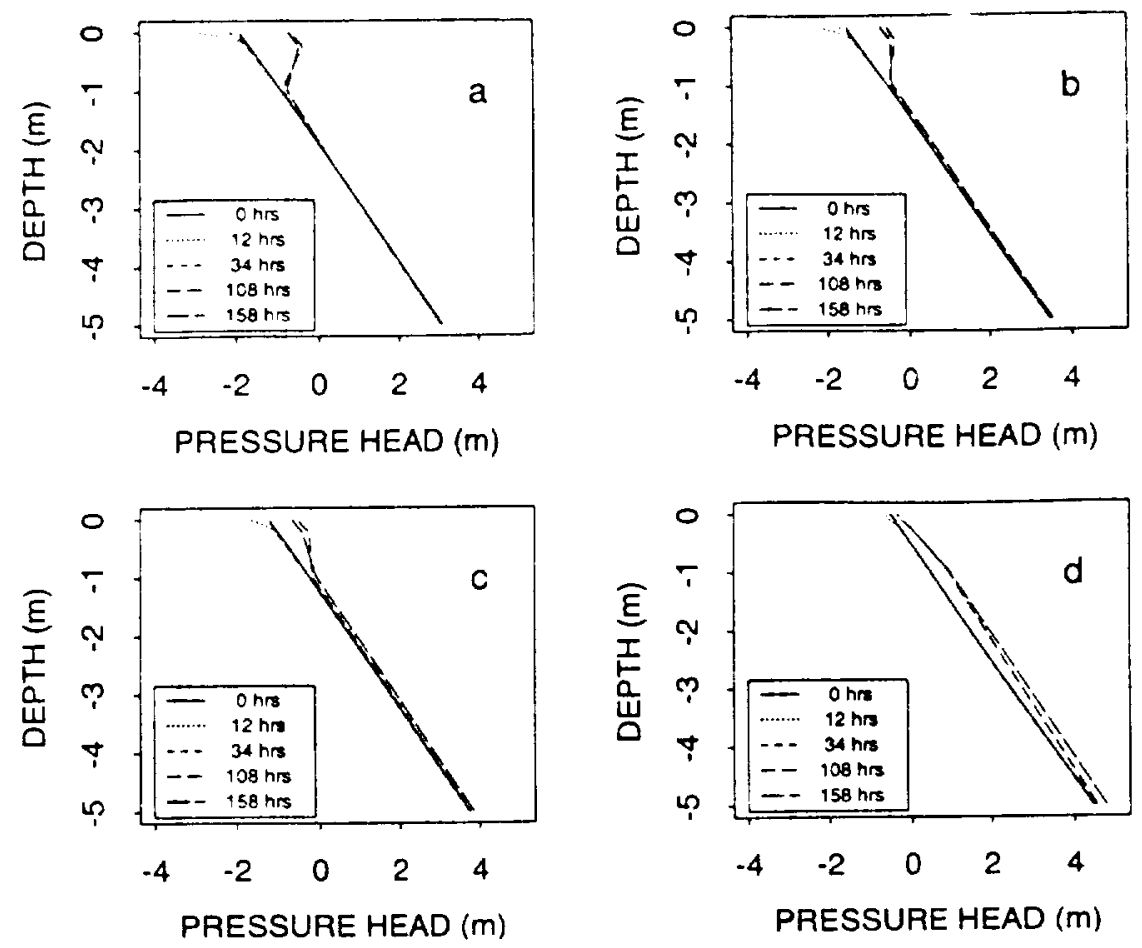

Fig. 9. Vertical pressure head profiles for five different time steps during the 12-day numerical simulation and at the four locations along the transect shown in Figure 8: $(a)$ node farthest from the channel: $(d)$ node closest to the channel.

in the upper $1 \mathrm{~m}$ of the unsaturated zone the pressure head profiles are not consistent with the hydraulic equilibrium assumption. This fact is detected for the pixels furthest from the stream where the water table is deepest. Below $1 \mathrm{~m}$ depth the simulated profiles do not deviate significantly from hydraulic equilibrium. Based on field evidence collected at the Mahantango Creek watershed, Gburek [1977] concluded that variation in soil moisture is limited to the upper $1 \mathrm{~m}$ layer, and that below this depth soil moisture content remains nearly constant and near field capacity throughout the year.

These results suggest that we can improve the conceptual model by using two layers instead of one to model the unsaturated zone. The upper layer in such a two-layer model can also incorporate root zone processes. This extension has been made to the conceptual model and is being tested on the First ISLSCP Field experiment (FIFE) data set from Kansas [Famiglietti, 1992; J. S. Famiglietti and E. F. Wood, Aggregation and scaling of spatially variable hydrological processes, 2, A catchment scale model of water an energy balance, submitted to Water Resources Research, 1993].

\subsection{Base Flow Recession Characteristics}

The parameters $a_{1}$ and $b_{1}$ of (22) in the case of an exponential subsurface saturated soil water store are given by

$$
a_{1}=f / A \quad b_{1}=2
$$

In contrast to observations for catchment WE-38 and subcatchment WD-38 (Figure 4) and to Boussinesq's hydraulic groundwater theory (equations (23)), the predicted subsurface flow contributions from the conceptual model will yield a slope of 2 on a $\log (d Q i d t)$ versus $\log Q$ diagram (see line
2 in Figure 10). We believe that this is not an unreasonable slope value for characterizing base flow recession in steeper catchments, where the influence of the hillslopes on groundwater flow is significant, at least during the initial stage of a recession period, and thus where Boussinesq's theory is not valid [Zecharias and Brutsaert, 1988]. For the catchments used in this study, however, topographic effects on base flow recession characteristics are negligible and base flow observations correspond to Boussinesq's groundwater equation and therefore give a slope close to 1.5 on the $\log (d Q / d t)$ versus $\log Q$ diagram. For catchments with mild slopes the

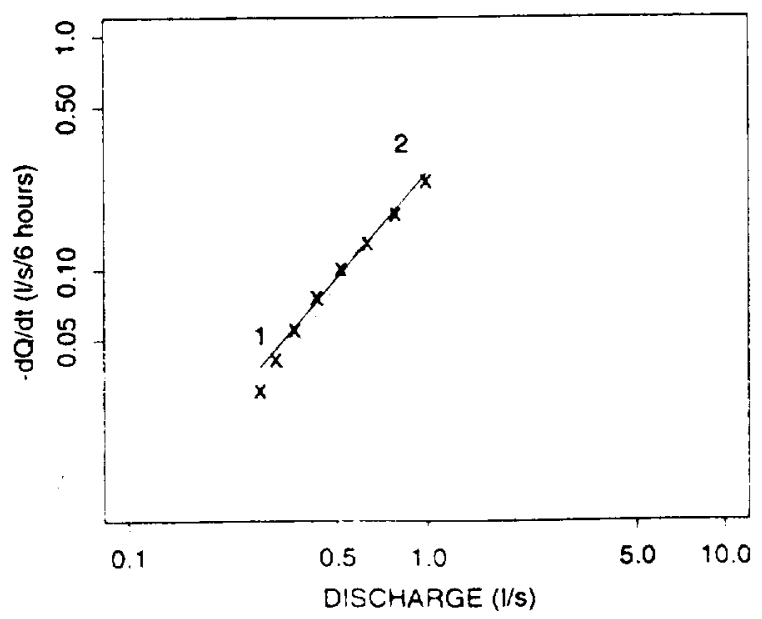

Fig. 10. Theoretical versus simulated base flow recession characteristics. X: log-log plot of $-d Q d$ versus discharge $Q$ for numerically simulated base flow contribution: line 1: least squares fit to the data points s sope 1.57): and line 2: theoretical base fow characteristic from the conceptual model (slope 2). 
base flow equation in the conceptual model should be modified in order to fully represent the recession dynamics.

Sirice the numerical model solves the three-dimensional Richards equation in an isotropic soil matrix it is not surprising that the calculated subsurface fow contributions (plotted points in Figure 10) during the drydown period in the simulation run for subcatchment WD-38 behave as predicted by Boussinesq's theory. In fact, the resulis from the numerical model yield a slope of 1.57 in Figure 10 (line 1).

Equations (25) offer the possibility of estimating the model parameter $f$ based on recession observations. By imposing a slope of 2 on the data displayed in a $\log (d Q / d t)$ versus $\log$ $Q$ diagram and by taking a lower envelope excluding $5 \%$ of the data, the value of the intercept can be calculated. Through the first of equations (25) a corresponding value of $f$ can then be estimated. In (25) the drainage area plays the role of a scaling factor. A similar technique can be used to determine the parameter $f$ in the numerical model. In future studies, different methods of calibrating both the numerical and conceptual models will be compared.

\section{SUMMARY}

The evaluation of a conceptual catchment scale water balance model is presented. This evaluation is based on a comparison of simulation results from the conceptual model with results from a three-dimensional physically based numerical model and with field observations. The conceptual model relies on a topographic index to predict saturation excess runoff and on Philip's equation to predict infiltration excess runoff. The numerical model is based on the threedimensional transient Richards equation. The study is carried out at two basin scales: a $7.2-\mathrm{km}^{2}$ catchment and a $0.64-\mathrm{km}^{2}$ subcatchment. These catchments are located in the North Appalachian ridge and valley region of eastern Pennsylvania. Detailed hydrologic data were collected for both catchments during the 12-day MACHYDRO 90 experiment.

Simplifying assumptions in the conceptual model concerning the spatial distribution and temporal evolution of water table depth, the distribution of soil moisture and pressure head in the unsaturated zone, and the characteristics of base flow recession are discussed. The hypothesis about the spatial and temporal evolution of local water table depth is tested by comparing the distribution of the topographic index with the distributions of the water table depth generated by the numerical model at the end of a 12-day simulation period. It is found that the use of a linear relationship between the local water table depth and the topographic index is reasonable in a basin scale water balance model. To test the effect of initial conditions, longer test runs with the numerical model are performed. Piezometric observations are compared to simulated groundwater dynamics. Close agreement between simulation results and field observations is obtained for shallow well observations. The hydraulic equilibrium assumption for the vertical distribution of soil moisture in the conceptual model is tested by examining the moisture profiles obtained from the numerical model. The results suggest that the conceptual model can be improved by using two hyers to model the unsaturated zone. The characteristics of base flow recession for the conceptual and numerical models are compared with analytical solutions to Boussinesq's hydraulic equation and with observations. Based on this comparison we suggest that streamflow reces- sion data can be used to calibrate hoth the conceptual model and the numerical model.

Further tests are required to confirm some of the findings discussed in this paper. Based on the 12-day simulation period for subcatchment WD-38 we conclude that the distribution of the topographic index is a reasonable measure for the local water table depth in Mahantango Creek. Detailed hydrologic data, as used in this study but for a longer period, are necessary to further justify this conclusion. The effect of catchment topography on the base flow recession characteristics, as suggested in section 4.4, should be further investigated. Other simplifying assumptions in the conceptual model, such as the calculation of soil moisture content. should be tested by comparing the simulation results with field observations and with remotely sensed information. A study comparing simulated soil moisture maps with soil moisture maps generated from remotely sensed information for WE-38 and WD-38 Mahantango Creek and based on MACHYDRO 90 data is in progress. This work will also involve extending some of the numerical simulation tests to WE-38 and to other catchments.

Acknowledgments. The work presented in this paper was supported by NASA (grant NAG 5-1628), U.S. Army Research Office (grant DAAL03-91-G-0165), USDA (grant 58-3K-47-0-039), and the Italian NRC (grant 91.02615.PF42): this research support is gratefully acknowledged. The authors wish to thank Dominique Thongs for processing the DEM data used in this study. Comments from three anonymous reviewers are highly appreciated.

\section{REFERENCES}

Band. L. E., Topographic partition of watersheds with digital elevation models, Water Resour. Res.. 22(1), 15-24, 1986.

Beven, K. J., On subsurface stormflow: An analysis of response times, Hydrol. Sci. J., 27(4), 505-521, 1982.

Beven, K. J., and M. J. Kirkby, A physically based, variable contributing area model of basin hydrology, Hydrol. Sci. Bull., 24(1), 43-69, 1979.

Binley, A. M., K. J. Beven, and J. Elgy, A physically based model of heterogeneous hillslopes, 2. Effective hydraulic conductivities, Water Resour. Res.. 25(6), 1227-1234, 1989.

Boussinesq. J.. Recherches théoriques sur l'écoulement des nappes d'eau infiltrées dans le sol et sur le débit des sources, J. Math. Pures Appl., 10, 5-78, 1904.

Brooks, R. H., and A. T. Corey, Hydraulic properties of porous media, Hydrol. Pap. 3. Colo. State Uniy., Fort Collins, 1964.

Brutsaert. $W$.. The concise formulation of diffusive sorption of water in a dry soil, Water Resour. Res.. 12(6). 1118-1124. 1976.

Brutsaert, W., and J. L. Nieber. Regionalized drought flow hydrographs from a mature glaciated plateau, Water Resour. Res., 13(3). 637-643, 1977.

Engman. E. T.. Partial area hydrology and its applications to water resources. Water Resour. Bull., 10, 512-521, 1974.

Engman, E. T., and A. S. Rogowski, A partial area model for storm flou synthesis, Water Re'seur. Re's., 10(3), 46t-472. 1974.

Faniglietti, J. S. Aggregation and scaling of spatially variable hydrological processes: local. catchment scale, and macroscale models of water and energy halance. Ph. D. dissertation, Dep. of Civ. Eng. and Oper. Res., Princeton Univ.. Princeton, N. J., 1992.

Famiglietti. J. S., E. F. Wood, M. Sivapalan, and D. J. Thongs, A catchment scale water halance model for FIFE. J. Goophys. Re's. 97(D17), 18,997-19.017. 1992.

Freeze, R. A., Three-dimensional. transient, saturated-unsaturated flow in a groundwater hasin, Watcr Resumer. Res.. 7(2), 347-306. 1971.

Frecye, R. A., and J. A Cherry. Cirmundwater, Prentice-Hall. Englewood Cliffi, N I 1979.

Cian, $\Gamma$. $Y$.. and $S$. J. Burges, An assewrnent of a conceptual ranfall-runoff model's athility on reprenent the dynamsen of smatl 
hypothetical catchments. 1. Models, model propertics, and experintental design. Water Resour. Re's.. 26(7), 1595-16014. 19910.

Gan. T. Y., and S. J. Burges. An assessment of a conceptual rainfall-runoff model's ability to represent the dynamics of small hypothetical catchments, 2, Hydrologic responses for normal and extreme rainfall. Water Re'sour. Re's. 26171, 1605-1620. 1990b.

Gburek, W. J.. The Mahantango Creek watershed. General hydrology and research results. in Procededings of the Smihsonian Watershed Research Workshop, edited by D. L. Correll. pp 227-250. Chesapeake Bay Center for Environmental Studies, Edgewater. Md.. 1977.

Gupta. V. K. and E. C. Waymire, On the formulation of an analytical approach to hydrologic response and similarity at the basin scale. J. Hydrol. 65, 95-123, 1983.

Gupta, V. K.. and E. C. Waymire. Statistical self-similarity in river networks parameterized by elevation. Water Resour. Res., 25(3). $463-476,1989$.

Hillel, D.. Applications of Soil Physics, Academic, San Diego, Calif., 1980.

Ibrahim, H. A., and W. Brutsaert, Intermittent infiltration into soils with hysteresis, J. Hydraul. Div. Am. Soc. Civ. Eng., 94(HY1), 113-137. 1968.

Loague, K. M.. and R. A. Freeze, A comparison of rainfall-runoff modeling techniques on small upland catchments, Water Resour. Res., 21(2). 229-248, 1985.

Mesa, O. J., and E. R. Miffin, On the relative role of hillslope and network geometry in hydrologic response, in Scale Prohlems in Hydrology, edited by V. K. Gupta, I. Rodriguez-Iturbe, and E. F. Wood, pp. 1-17, D. Reidel, Norwell, Mass., 1986.

Paniconi, C. Hydrologic processes in variably saturated porous media: Analysis of numerical methods for solving the nonlinear Richards equation. and application to catchment scale simulations. Ph.D. dissertation, Dep. of Civ. Eng. and Oper. Res., Princeton University, Princeton, N. J., 1992.

Paniconi, C., and E. F. Wood, A detailed model for simulation of catchment scale subsurface hydrologic processes, Water Resour. Res., in press, 1993.

Paniconi, C., A. A. Aldama, and E. F. Wood, Numerical evaluation of iterative and noniterative methods for the solution of the nonlinear Richards equation, Water Resour. Res., 27(6), 1147$1163,1991$.

Philip, J. R. The theory of infiltration, 1. The infiltration equation and its solution, Soil Sci., 83, 345-357. 1957a.

Philip, J. R., The theory of infiltration, 2. The profile at infinity, Soil Sci., 83, 435-448, 1957b.

Polubarinova-Kochina, P. Y., Theory of Ground Water Movement, translated from Russian by R. J. M. De Wiest, Princeton University Press, Princeton, N. J., 1962.

Reeves, M., and E. E. Miller, Estimating infiltration for erratic rainfall, Water Resour. Res., I/(1), 102-110, 1975.

Rogowski, A. S., E. T. Engman, and E. L. Jacoby, Transient response of a layered, sloping soil to natural rainfall in the presence of a shallow water table, Experimental results, Rep.
ARS-NE-30, Agric. Res. Serv., L.S. Dep. of Agric.. Hyatsville. 11. D.. 1974 .

Sivapalian. M.. and E. F. Wood. spatial heterogeneity and scale in the infiltration reuponse of catchments. in Scale Problems in Hydrolegy, edited by V.K. Gupta. I. Rodriguez-llurbe, and $\mathrm{E} . \mathrm{F}$. Wood. pp. 81-106. D. Reidel. Norwell, Mass., 1986

Sivapalan. M. K. J. Beven, and E. F. Wood. On hydrologic similarity. 2. A scialed model of storm runoff production. Water Resour. Re's.. 23(12). 2266-2278. 1987.

Sloan, P. G.. and I. D Moore. Modeling subsurface stormflow on sleeply sloping forested watersheds. Hater Resour. Res., 20112). $181.5-1822,1984$

Smith. R. E.. and R.H.B. Hebbert, Mathematical simulation of interdependent surface and subiurtice hydrologic processes. Wator Resuler. Re's., 19(41, 987-1(x)1. 1983.

Tarbotun. D. G.. R. L. Bras, and 1. Rodriguez-Iturbe. Scaling and elevation in river networhs. Water Resour. Re's.. 25(9), 20372051. 1989 .

Troch. P. A., F. P. De Troch, and W. Brutsaer, Effertive water table depth to describe initial conditions prior to storm rainfall in humid regions. Water Resour. Res.. 2912), 427-434, 1993.

Urban. J. B.. The Mahantango Creek watershed, Evaluating the shallow groundwater regime, in Proceedings of the Smithsonian Watershed Research Workshop. edited by D. L. Correll, pp. 251-274, Chesapeake Bay Center for Environmental Studies. Edgewater. Md.. 1977.

van Genuchien, M. T., and D. R. Nielsen, On describing and predicting the hydraulic properties of unsaturated soils. $A n n$. Geophys., 315), 615-628, 1985.

Wood. E. F., M. Sivapalan, K. J. Beven, and L. E. Band, Effects of spatial variability and scale with implications to hydrologic modeling, J. Hydrol.. 102, 29-47, 1988.

Wood, E. F., M. Sivapalan, and K. Beven, Similarity and scale in catchment storm response, Rev. Geophys., 28(1), 1-18, 1990.

Zecharias, Y, B.. and W. Brutsaert. Recession characteristics of groundwater outflow from mountainous watersheds, Water Resour. Res., 24(10), 1651-1658, 1988.

M. Mancini, Dipartimento di Ingegneria Idraulica, Ambientale e del Rilevamento. Politecnico di Milano. Piazza Leonardo da Vinci, Milano, laly.

C. Paniconi, CRS4. Via Nazario Sauro 10, 1-09123 Cagliari, Italy. P. A. Troch, Laboratory of Hydrology and Water Management, Ghent University. Coupure Links 653, B9000 Gent, Belgium.

E. F. Wood, Water Resources Program. Department of Civil Engineering and Operations Research, Princeton University, Princeton, NJ 08544.
(Received July 15, 199?: revised January 27, 1993; accepted February 15, 1993.) 
